\title{
EXPOSURE-STANCE CONCEPT MODEL
}

\author{
A.M.R. Abante \\ Bicol University College of Engineering, Legazpi City, Philippines - anamarie.abante@ bicol-u.edu.ph
}

KEY WORDS: Exposure-stance, proximity, accessibility, connectivity, risk reality, OSM

\begin{abstract}
:
The paper presents an exposure-stance concept model with three basic elements: proximity regarded as a measurement of nearness, accessibility which refers to the road stance serviceability that convey the people or goods from place to place by means of a vehicle, and connectivity of uncontrolled activities i.e. road and/or building constructions, nearness (measurement) information to be reached from or to be reached by to transport people and resources regardless if it traverses the danger or hazard zones in the slopes of Mayon Volcano. The challenging work is modelling the level of exposure-stances operationally defined as the accessibility in terms of road stance serviceability, connectivity in terms of road constructed and building footprints' nearness measurement with danger or hazard zones relative to the risk reality phenomenon information happening in Mayon Volcano. This paper practically highlighted results, specifically on the matrix of levels of exposure-stances contexts that creates knowledge prompted by spatial information (nearness measurements) featuring accessibility, connectivity, proximity, risk reality, danger and hazards zones, and OSM roads and building footprints variables. The study concluded that rejecting roads and building (lines and polygons) mimics the perpetual relocation of exposed residents. Also, closing the proclaimed protected forest areas to any activities will likely nil exposure, thus lowering risk hotspot level of significance. Hence, nulling exposure stance variable if not dispersing exposure featuring roads and buildings within the protected areas, development constraint areas, and permanent and extended danger zones of Mayon Volcano has a practical implication to stabilize and sustain developments at the foot slopes of the volcano.
\end{abstract}

\section{INTRODUCTION}

\subsection{Framework for Exposure-Stances}

The exposure-stance concept model was based on the Geophilosophy on Risk Realness of (Abante, 2021a,b,c) and the exposure-happenstance (Abante, 2019) combining the theories of Olsson (2009) and Hansen (1959) on accessibility, Levinson, and Huang (2012) theory on network connectivity, as well as the proximity theory (Milla, et.al, 2005) which substantiates the exposure-stance as an independent variable of risk reality phenomenon (Abante, 2021c). The exposure-stance variable is the result of intersecting three spaces, mathematically expressed as the sets of \{Exposure-Stance $\sim$ \{Proximity $\cap$ $\{$ Connectivity $\cap \cap\{$ Accessibility $\}$.

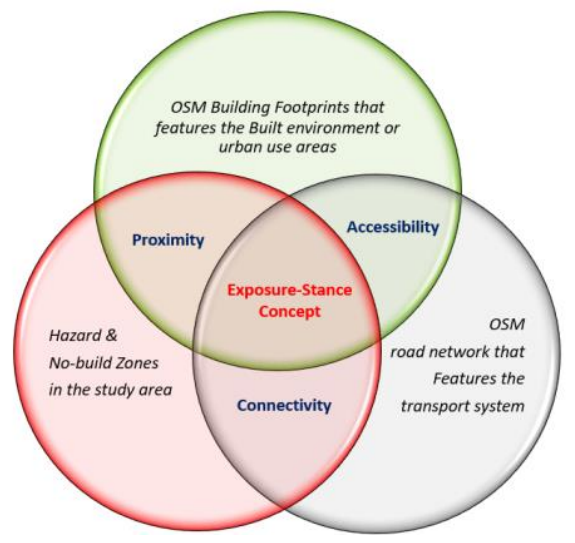

Figure 1. Exposure-Stance Concept Model

The 'accessibility element' of ES in this work refers to the characteristics of the transport system that convey the people or goods from place to place by means of a vehicle that is inspired by the accessibility theory of Ariel (2001). The operational definition of accessibility element describes how access increased road right-of-way procedures expresses options to road users, residents, and land property owners to use a certain planned or nor properly planned road access for settlement. Right-of-ways in this study refers to roads classified as national, provincial, city or municipal that interconnect barangay centers, and private subdivision streets. The unplanned or not properly planned access are those roads that traverse the lahar prone areas or the Mayon permanent danger zones including those roads or earth roads used to haul gravel and sand, farm-to-market roads supposedly constructed to deliver agricultural products within the danger zones.

The 'connectivity element' in this study refers to the geographical locations to be reached from or to be reached by to transport farmers' agricultural products, and the Mayon gravel and sand. The operational definition of connectivity element describes the network connectivity which provides a line topology interconnecting the relationship roads and land properties (parcels) and its economic value of agricultural crops and gravel and sand, considering most of the areas of the volcano are classified as alienable and disposable lands.

The influence the location (x,y) (Abante, 2021a,b,c; 2019; 2018) of OSM building footprints featuring the settlements forming the communities' identity (Bankoff et.al., 2021) around the Mount Mayon foot slopes, although local historical cultural memory (Bankoff et.al., 2021) is likely to have little lasting effect on reducing people's vulnerability residing near the permanent and extended danger zones. The 'proximity element' of ES in this study is regarded as a measurement of nearness of OSM building footprints to establish the relationship between distance and the hazard and/or no-build zones using the GIS tool.

The concept of exposure-stance (ES) offers useful applications to a variety of work. In exposure assessment, exposure-stances are referred to as points on a given spatial setting that act as a symbol underlying the level of exposure at its significance as an independent variable of risk. Likely, exposure-stances are established to help analyze risk reality phenomena relative to the adaptive capacity expressed as the ratio of hazards and 
preparedness (Abante, 2021b,c; Abante, 2018), sensitivity expressed as the ratio of landscape vulnerability and competency of people living in the danger zone (Abante, 2021a,b,c; Abante \& Abante, 2018, 2019) and their relationship with coping capacity and risk element (Abante, 2021a,b,c; Abante \& Abante, 2018, 2019).

Characterization of exposure (Lee, et.al, 2013) is a central issue in the analysis of observational data; however, no "one size fits all" solution exists for exposure measurement.

The exposure-happenstance (Abante, 2019) study linked the traders through the road networks (originally horse trails) leading to abaca farm lots and interconnecting the urban centers or "población" to isolated rural settlements called the "barrios" or "sittios" in the 1800s. The OSM roads and building footprints was used to map the exposure-happenstance by overlaying the disaster risk patterns, categorized as follows: disaster risk-prone areas; near disaster risk-prone areas; somewhat risky areas; random values, somewhat safe area; near the resilient area; and resilient areas, in the ArcGIS platform.

\subsection{Study Area}

The Philippines is the third most disaster-prone country in the world according to the World Bank. (Pellini, et al., 2013) submits that there is low uptake of research and analytic thinking to inform local decision making on disaster risk management. Albay's undesired land developments (both permanent and temporary building structures) are mostly built along the rightof-way such as barangay/purok roads, farm-to-market roads, trails and tracks of trucks hauling the gravels and sands needed to develop cities and municipalities, dikes, evacuation routes, and so on. The barangay nodal centers or the location of the barangay halls surrounded by buildings mostly utilized for dwelling and socioeconomic purposes where roads interconnect the developments in the study area.

\subsection{Research problem and objectives}

The exposure-happenstance (Abante, 2019) characterized the access and interconnectivity of settlements and roads to observe the OSM road and building footprints which traverse disasterprone areas at different levels. The research problem of this study focuses on the issue of exposure due to accessing gravel and sand resources within the National Integrated Protected Areas System (NIPAS), considering this space will hypothetically reduce the risk reality by nulling exposure and prevent a disaster.

The main objective of the study is contextualizing the exposure stances taking in the three elements: accessibility in terms of road serviceability, connectivity to the nearest dangerous or hazard areas, and proximity in terms of the nearness measurement of building footprints existences within the danger zones or risk hotspots and NIPAS covered area. The study aims to include those three elements in risk computing to further contextualize exposure. Specifically, the study aims to answer the following: (i) which OSM roads provide connectivity and accessibility information to reach OSM building footprints which represents the transportation system for people, agricultural products, and gravel and sand, and other goods, (ii) how can OSM building footprints symbolize the underlying level of exposure as it marks its position which hints position is at risk or exposed.

\section{MAIN BODY}

\subsection{Fundamentals of Exposure}

The exposure situation or nearness (Abante, 2021a,b,c; 2019, 2018) which specifically refers to an OSM building and/or road coincidence (passive exposure) given the highest score and were extracted by buffering the lines (OSM road) and polygons (OSM buildings) with 100 meters to represent nearness or density as well as the exposure-happenstance (Abante, 2019) regarded as spatial patterns (points and lines) which disclosed the undesired developments setting off complexities in disaster risk reduction within the Mayon permanent and extended danger zones. She stressed that the exposure-happenstance visualization and statistical information can spur imposition of a No-build Zone policy or can stir relocating to safer places. Both studies highlighted nil exposure refers to non-interaction (avoiding rather than mitigating) the vulnerable space, thus realizing nil exposure within the Mayon danger zones remains doubtful. Furthermore, her study also raised the issue that extraneous errors are inherent in measuring the risk reality phenomenon (Abante, 2021c).

The idea of indirect development (Olsson, 2009) affects the road accessibility to respond to economic opportunities. He used timeseries data, a road accessibility inventory, and a multi-criterion to analyze the indirect effects of improvements in the rural areas in the Philippines which characterizes the poor transport conditions and poor accessibility to major markets. He said that the road improvements considerably benefited the fishing communities. He stressed that the practical implication of road improvements complements the abundance of harvested resources in the community and increase in the production demand.

The residential development patterns to illustrate accessibility (Hansen, 1959) to vacant lots that are developable as the basis of a residential land use model. He suggested a method for determining accessibility patterns within metropolitan areas to process the projected population distribution in the metropolitan region relative to the land use. The accessibility theory (Ariel, 2001) described how humans are responsive to the facts about human memory where memory nodes are nor equally activated at a given time. He said that his theory offers a procedural analysis referring to expression, as making varying degrees of mental accessibility. The basic idea referred was expressions instruct the addressee to retrieve a certain piece of given information from his memory by indicating to him how accessible the said given information is to him at the current stage of the discourse.

The positive theory of network connectivity (Levinson and Huang, 2012) provides a micro foundation of alternative network topologies as the result of self-interested actors. To them building roads offers landowners hope to increase their parcels' accessibility and economic value. They used a grid-like land-use layer with a downtown in the center to examine the tree-like structure where the road network topology becomes increasingly connected as the accessibility value of reaching other parcels increases. The results demonstrate that, even without a centralized authority, road networks can display the property of self-organization and evolution, and that, in the absence of intervention, the degree to which a network structure is tree-like or web-like results from the underlying economies.

The theory on unobtrusive exposure to personality trait terms suggested that "reckless" or "persistent" terms (Higgins, et.al, 
1977) were not in itself sufficient to determine attributions and evaluations which implied variation in the accessibility of different categories for judgments.

The research on road network characteristics based on proximity (Wang, et.al, 2017) employs a statistical method to measure proximity using graph theory. The relative neighborhood (Wang, et.al, 2017) characterized by the Beijing Road network supported the network analysis.

The GIS was used to evaluate the effects of proximity (Milla, et.al, 2005) to hog farms on residential properties. The applicability of GIS-based hedonic price modeling (Milla, et.al, 2005) for evaluating impacts to residential property values from feeding operations, particularly hog operations. The relationship between distance to hog farms and property sales prices, in which the results indicated a negative and significant impact on property value from hog operations giving emphasis on GIS as tool to assess property value damages associated with animal operations, for evaluating potential impacts when citing new operations, and for developing setback guidelines (Milla, et.al, 2005).

\subsection{GIS modeling approach and ES contextualization}

The challenging work is modelling as shown in Figure 2 the level of exposure-stances brought by taking its elements in which the proximity to no-build zones which outlines the binned nearness information stored and sorted in a hexagonal polygon to purposefully measure in an obvious way to analyze points and polylines features with proximity tools in ArcGIS platform. Similarly, the accessibility variable features the binned roaddensity that is represented by lines that characterizes the types and functions of the road network relative to the position of the building footprints. The connectivity variable features the binned density of connections of road centerlines that crosses the hazard or no-build zones. The GIM carried the analysis for common scale values to diverse and dissimilar inputs (elements of exposure-stances which create an integrated analysis to extract the science-based information (output) which practically highlighted the different levels of exposure-stances.

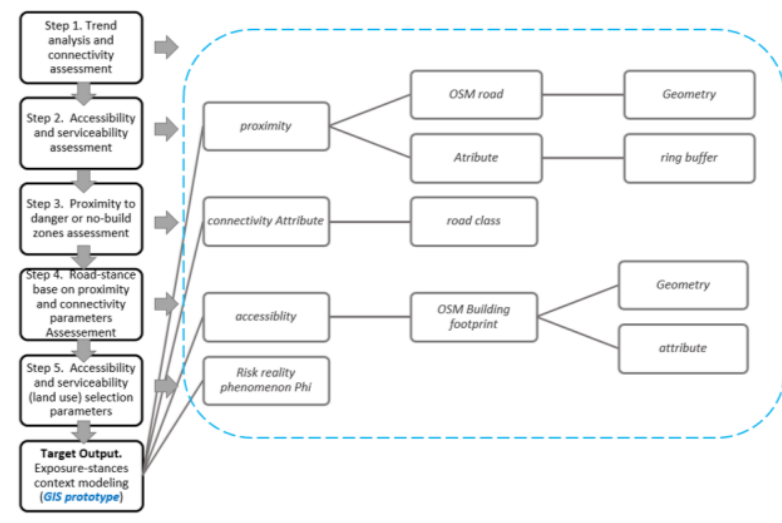

Figure 2. GIS Modeling Approach and ES Contextualization

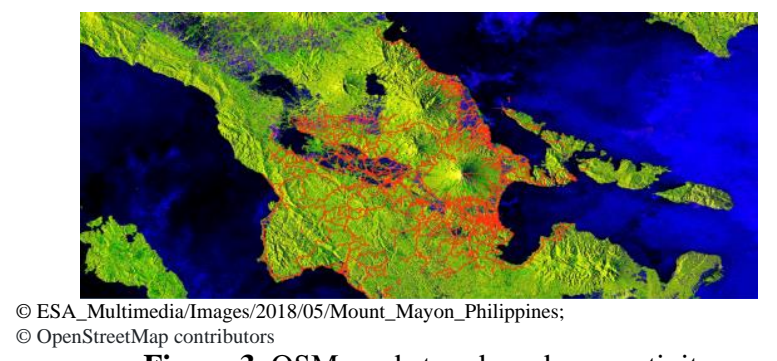

Figure 3. OSM roads trends and connectivity

\subsubsection{Trend analysis and connectivity assessment}

The connectivity variable features the binned density of connections of road centerlines that crosses the hazard or nobuild zones. The line connectivity and intersection information were overlaid with hexagonal bins to extract the five categories of connectivity. Figure 3 shows the OSM roads feature in the study area.

\subsubsection{Accessibility and serviceability assessment}

The accessibility variable features the serviceability symbolized by OSM building footprints. The building incidence information was overlaid with hexagonal bins to extract the five categories of accessibility. Figure 4 shows the OSM buildings featuring service areas around or within the foot slopes of the Mayon volcano.

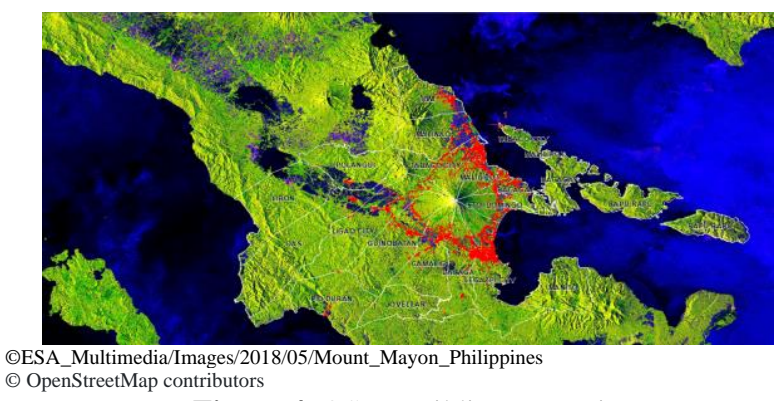

Figure 4. OSM Building Footprints

\subsubsection{Proximity to danger or no-build zones assessment}

The proximity variable outlines the nearness to danger or nobuild zones as shown in Figure 5 to store and sort information in a hexagonal polygon to purposefully measure in an obvious way to analyze points and polylines features with proximity tools in ArcGIS platform. The lava and lahar prone areas, risk hotspots with $99 \%$ level of confidence, remaining forest area covered by the NIPAS law were overlaid with the hexagonal bins to extract the tessellated five categories of proximity.

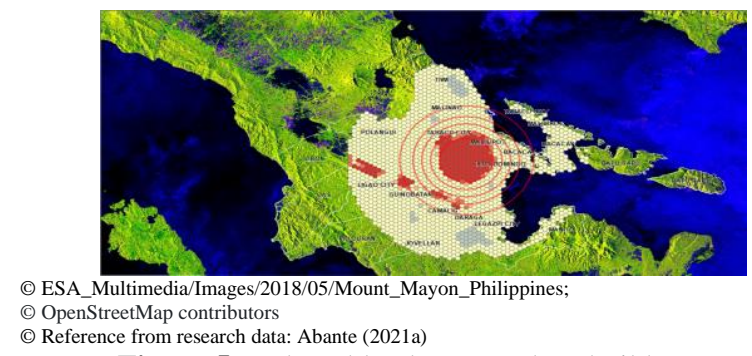

Figure 5. Vulnerable, danger and no-build zones

\subsection{Risk reality information}

This study analyzed tessellated bins that practically measure risk reality (Abante, 2021a,b,c) as one of the parameters to examine the research variables in macro level perspective. The bins stored and sorted the risk elements in a hexagon to visualize the spatial representations of risk elements. The risk map was used to further examine the aspects of proximity, accessibility and connectivity variables that will define the elements of exposurestances spatial patterns which disclosed the significance of extending roads and rising building counts that feature the exposure-stances as shown in Table 4. 


\subsection{Exposure-stance contextualization}

The exposure-stance in this study was contextualized using the road-stance information base on proximity and connectivity parameters paired with exposed land selection parameters.

\subsubsection{Road-stance base on proximity and connectivity parameters}

Road-stances are feature-based (binned information) using proximity tools resulting from analyzing the connectivity of OSM polylines relative to the Mayon permanent and extended danger zones and NIPAS covered area.

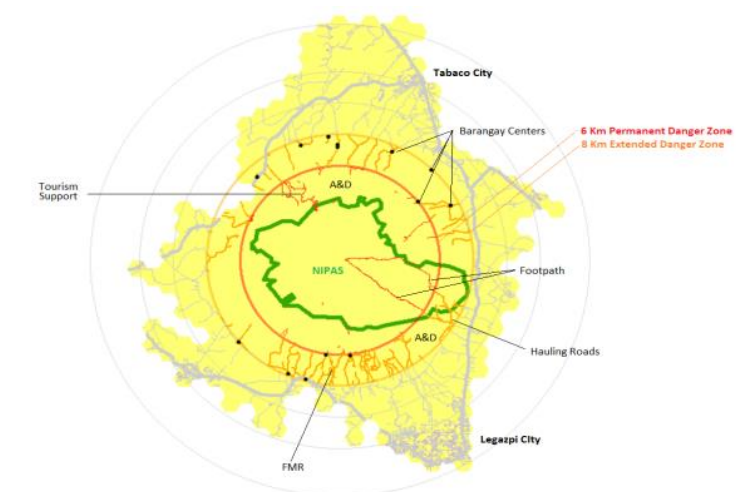

() LC Maps for Mt. Mayon of DENR R5

(C) OpenStreetMap contributors

() Reference from research data: Abante (2021a,b,c, 2019, 2018), Abante \& Abante (2018), Abante \& Balilo (2018)

\section{Figure 6. Road-stances within the study area}

The road-stance parameters in this study refers to the following: (a) Level 1 refers to the proximity (nearness distance attribute) of OSM roads located within the 12 to $15 \mathrm{Km}$ comprising the national, provincial, city or municipal road, barangay and other roads or streets shown in Figure 3; (b) Level 2 refers to the proximity (nearness distance attribute) of OSM roads located within the 10 to $12 \mathrm{Km}$ comprising the national, provincial, city or municipal road, barangay and other roads or streets; (c) Level 3 refers to the proximity (nearness distance attribute) of OSM roads located within the 8 to $10 \mathrm{Km}$ comprising the national, provincial, city or municipal road, barangay and other roads or streets shown in; (d) Level 4 refers to the proximity (nearness distance attribute) of OSM roads located within the Mayon extended danger zone or within the 6 to $8 \mathrm{Km}$ comprising the city or municipal road, barangay, tourism support, farm-to-market, hauling and other roads or right-of-way or footpaths shown Figure 4; and Level 5 refers to the proximity (nearness distance attribute) of OSM roads located within the Mayon permanent danger zone or within the $6 \mathrm{Km}$ comprising the city or barangay inroads to access the barangay centers located within the extended danger zone or near the permanent danger zone, tourism support, farm-to-market, hauling and other roads or footpaths.

2.3.2 Accessibility and serviceability (land use) selection parameters

The criteria used to analyze the accessibility and serviceability (land use) within the study area are as follows: (i) 99\% risk hotspot or lava prone areas as shown in Figure 7 a \& b, (ii) lahar prone areas or source of gravel and sand (for infrastructure projects or development needs) within the permanent danger zones or $90 \%$ to $95 \%$ risk hotspot with OSM building footprints stances as shown in Figure 7a\&b and Figure 8; (iii) agricultural lands are within the alienable and disposable lands exterior to the NIPAS covered area as shown in Figure $7 \mathrm{a}$ where buildings are allowed within these areas regardless of the danger or risk is significant or not; (iv) within the A\&D as shown in Figure 7a gravel and sand extraction sites are regulated regardless of the risk reality significance; and (v) areas not within the Mayon permanent of extended danger zones as shown in Figure 7 remain vulnerable to low to high susceptibility to lahar specially when extreme rainfall trigger rain-induced landslide within the lava and lahar prone areas producing sand and gravel deposited in gullies, rivers and creeks ready for extraction of raw material for infrastructure projects (Abante, 2021c; Abante \& Balilo 2018). According to Mines and Geoscience Bureau, Department of Environment and Natural Resource in Bicol Region, the probable landslide scenario in Mayon vicinity may vary: (i) warning level 0 may imply at least $10 \%$ rain-induced landslide probability; (ii) warning level 1 may imply $10 \%$ to $50 \%$ rain-induced landslide probability if rain intensify; (iii) warning level 2 may imply 50\% to $90 \%$ rain-induced landslide probability if rain intensify within 24 hours specifically is areas with modified slopes (e.g. road cuts); and (iv) warning level 2 may imply $>90 \%$ multiple or widespread rain-induced landslide probability if rain intensify within 24 hours (Abante, 2021c; Abante \& Balilo, 2018).

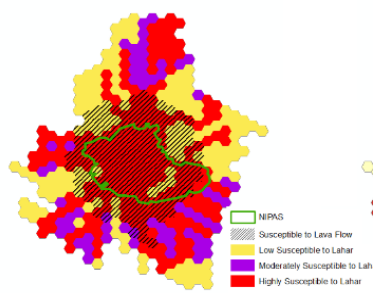

(a)

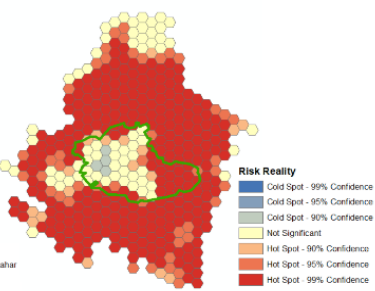

(b)
() Geohazard Maps of MGB-DENR R5

(c) LC Maps for Mt. Mayon of DENR R5

() Risk reality. DOI: $10.1007 / \mathrm{s} 42452-021-04442-6$

() OpenStreetMap contributors

Figure 7. Source of gravel \& sand vs. Risk reality

Figure 8 \& 9 disclose the following: i) not all the lava and lahar prone areas are covered by NIPAS, (ii) the NIPAS covered area as shown in Figure 8 disclose the risk of coldspot areas hinting a highest-best-land use confirming the forested areas within the NIPAS border, (iii) the $99 \%$ risk hotspot level of confidence within the NIPAS border as shown in Figure 8 hinted at encroachments within the protected forest zone as shown in Figure 8.

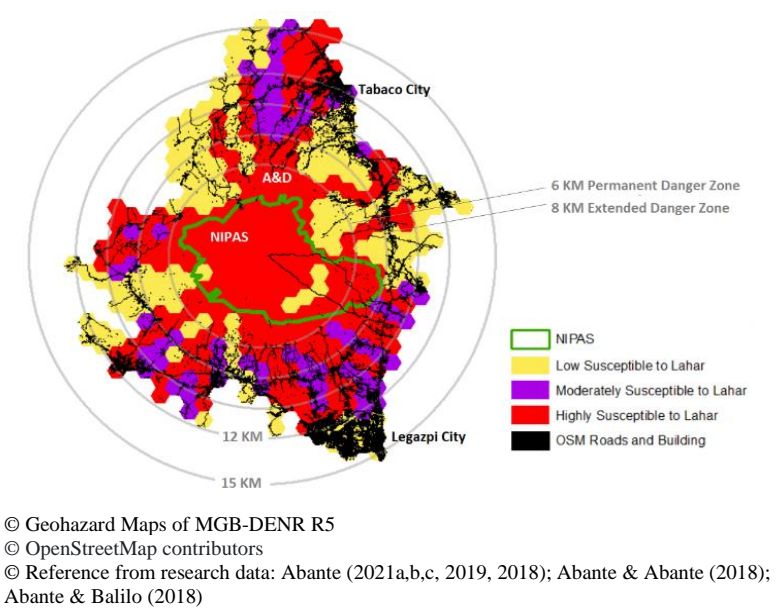

(1) Reference from research data: Abante (2021a,b,c, 2019, 2018); Abante \& Abante (2018);
Abante \& Balilo (2018)

Figure 8. OSM roads \& building within A\&D \& NIPAS $\&$ Lahar prone areas 
Figure $7 \& 8$ disclosed the following: (i) permanent danger zone relatively coincides with the landscape vulnerability hotspot and the areas susceptible to lava flow as shown in Figure 8. However, the NIPAS do not wholly cover these areas, and (ii) NIPAS covers portions of the $8 \mathrm{~km}$ extended danger zone, and (iii) the NIPAS within the extended danger zone are encroached with OSM building footprints and roads and right-of-way. Furthermore, the following barangay centers or Barangay Halls are situated within: (i) $99 \%$ risk hotspot areas at the same time located within the $8 \mathrm{Km}$ extended danger zone, these are: Quirangay (Camalig); (Salugan (Camalig); Maninila (Guinobatan); Canaway (Malilipot); San Roque (Malilipot); Buang (now Mayon) (Tabaco City); Oson (Tabaco City); Bonot (Tabaco City); San Isidro (Tabaco City), and (ii) 99\% risk hotspot areas at the same time located within or very near the 6 $\mathrm{Km}$ permanent danger zone, these are: Calbayog (Malilipot); Magapo (Tabaco City); Miisi (already relocated to Anislag, Daraga) and Anoling (already relocated to Bongabong, Camalig). Similarly, according to the Provincial Human Settlement Office of the Provincial Government of Albay (PGA) as of 2020 after Super Typhoon Rolly (Ulysses), there are 774 and 194 households that were affected by lahar and rain-induced landslides respectively. Likewise, according to the Philippine Institute of Volcanology and Seismology, MGB-DENR, the PGA, there are at least 23,354 housing units to relocate exposed families. The counting (aspatial) was done by hand or through reports (Abante, 2021a,b,c; Abante \& Balilo 2018).

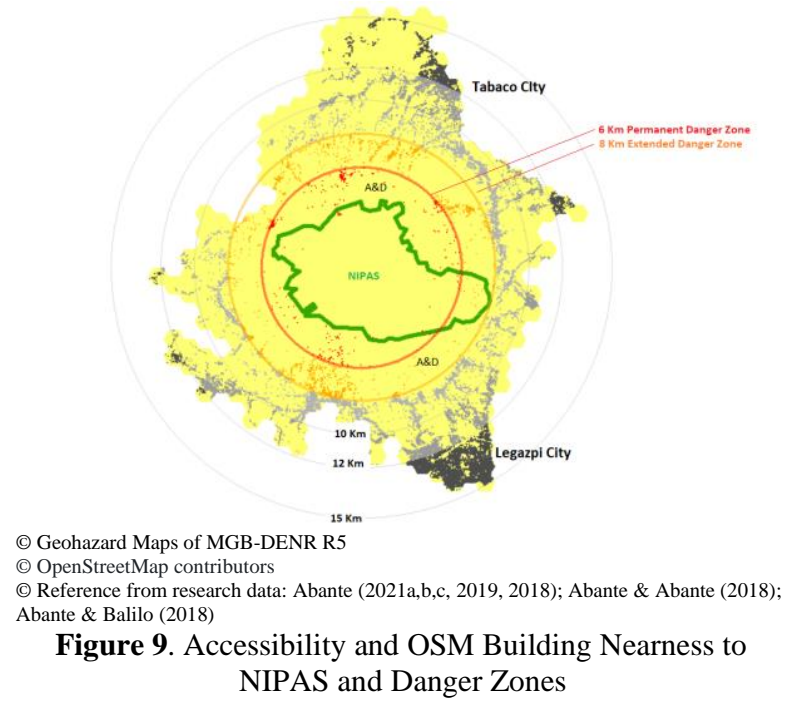

Figure 9 disclose the OSM building footprints that are located within: (1) lava and lahar prone areas as shown in Figure 8, (ii) risk hotspots; (iii) NIPAS covered areas, and (iv) permanent danger zones that are not covered by NIPAS. It hinted at difficulty in controlling the access or construction of buildings (land use) within the NIPAS covered (protection) area, and permanent and extended danger (production) zones within the A\&D areas substantiating the higher the OSM building density the higher the number of accessing or utilizing the land.

\subsection{Exposure-stance context model}

The researcher agrees with Higgins, et.al (1977) that understated exposure hinted at vitiating opinions on accessibility. This term is used in this study to understand the reckless act or persistence to access the natural resources such as gravel and sand and the crops of the fertile land sometime discarding the importance of the rules and regulations on allowed uses on an exposed land. The framework for exposure-stances as shown in Figure 1, steers the geospatial information modeling which carried the analysis for the level of exposure-stances resulted from examining the road connectivity based on the Olsson (2009) notion on indirect development to respond to economic opportunities trending in the study area, accessibility (serviceability in terms of land use) based on the accessibility theory (Ariel, 2001) which offers a procedural analysis to retrieve a certain piece of given information at the current stage of the discourse, and road network characteristics based in proximity (Wang, et.al, 2017) which employed a statistical method to measure proximity disclosed the applicability of GIS modeling to measure the near distance to danger and no-build zones.

\subsubsection{OSM road-stance and exposure level}

The OSM road-stance and exposure level: (i) connectivity of paths and right-of-way within the NIPAS covered area and $6 \mathrm{~km}$ permanent and/or danger zone denoting the road-stance and exposure level 5; (ii) connectivity of paths and right-of-way within the NIPAS covered area and/or $8 \mathrm{~km}$ extended danger zone denoted as the road-stance and exposure level 4; (iii) the road-stance and exposure levels 1 to 3 are roads or streets and right-of-way or footpaths outside the NIPAS covered area and danger zones. Figure 8 and 9 shows the access (barangay) roads or farm-to-market or hauling road and footpaths or tourism support roads traversing the NIPAS covered area and danger zones. The road-stance exposure levels 4 and 5 comprises the paths or right-of-way to access the agricultural lands within the A\&D lands or quarry sites near the gullies and drainage systems within the Mayon volcano. It also shows that the NIPAS remain open to trespassers (Abante, 2021c; Abante \& Balilo, 2018).

\subsubsection{Road Proximity to protection and danger zones}

Table 1 disclosed the lengths and weights of access roads and/or pathways within danger zones as well as pathways utilized to haul gravel and sand resources for infrastructure projects within and outside the study area.

\begin{tabular}{|c|c|c|c|c|}
\hline \multirow{2}{*}{\multicolumn{2}{|c|}{$\begin{array}{c}\text { Danger zones \& } \\
\text { Protection zone encroachment }\end{array}$}} & \multicolumn{3}{|c|}{$\begin{array}{l}\text { Length and weight of access road and/or } \\
\text { pathways by danger zones in Km }\end{array}$} \\
\hline & & \multirow{2}{*}{$\begin{array}{c}\text { Weight } \\
5\end{array}$} & \multirow[t]{2}{*}{$\begin{array}{l}\text { Protection } \\
\text { zone }\end{array}$} & \multirow{2}{*}{$\begin{array}{c}\begin{array}{c}\text { Danger/ } \\
\text { Hazard Zones }\end{array} \\
37.98\end{array}$} \\
\hline 1 & $\begin{array}{l}6 \mathrm{Km} \text { permanent danger } \\
\text { zone }\end{array}$ & & & \\
\hline 2 & $\begin{array}{l}6 \text { to } 8 \mathrm{Km} \text { extended danger } \\
\text { zone }\end{array}$ & 4 & & 117.71 \\
\hline 3 & $\begin{array}{l}\text { Extremely susceptible to } \\
\text { lahar }\end{array}$ & 5 & & 309.33 \\
\hline 4 & Highly susceptible to lahar & 4 & & 169.37 \\
\hline 5 & $\begin{array}{l}\text { Moderately susceptible to } \\
\text { lahar }\end{array}$ & 3 & & 342.22 \\
\hline 6 & $\begin{array}{l}\text { Extremely susceptible to } \\
\text { lava flow }\end{array}$ & 5 & & 89.44 \\
\hline 7 & $\begin{array}{l}\text { Extremely susceptible to } \\
\text { rain-induced landslide }\end{array}$ & 5 & & 98.02 \\
\hline 8 & $\begin{array}{l}\text { Highly susceptible to rain- } \\
\text { induced landslide }\end{array}$ & 4 & & 3.66 \\
\hline 9 & $\begin{array}{l}\text { Moderately susceptible to } \\
\text { rain-induced landslide }\end{array}$ & 3 & & 84.28 \\
\hline $\begin{array}{l}1 \\
0\end{array}$ & NIPAS encroachment & & 19.053 & \\
\hline $\begin{array}{l}\text { Raw } \\
\text { O Ge } \\
\text { O } L C \\
\text { O Op } \\
\text { O Re } \\
\text { Aban }\end{array}$ & $\begin{array}{l}\text { input data source: } \\
\text { zard Maps of MGB-DENR R5 } \\
\text { ps for Mt. Mayon of DENR R5 } \\
\text { reetMap contributors } \\
\text { cee from research data: Abante } \\
\text { Balilo (2018) }\end{array}$ & 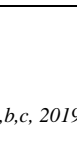 & be & (2018); \\
\hline
\end{tabular}

\subsubsection{Connectivity and OSM road Classification}


Although the connectivity can be measured at the joints of roads and pathways, this study focused on the road type attribution such as national, provincial, city or municipal, barangay of farmto-market roads or private roads, and pathways or hauling roads to visualize the patterns or variability of connectivity variable as shown in Table 2.

\begin{tabular}{|l|c|c|c|}
\hline \multirow{2}{*}{ Road Serviceability } & \multicolumn{3}{|c|}{ Length of path or access road in km } \\
\cline { 2 - 4 } & $\begin{array}{c}\text { Permanent } \\
\text { and Extended } \\
\text { Danger } \\
\text { Zones }\end{array}$ & $\begin{array}{c}\text { Lava flow } \\
\text { prone with } \\
\text { high Lahar } \\
\text { deposits }\end{array}$ & $\begin{array}{c}\text { Rain- } \\
\text { induced } \\
\text { landslide } \\
\text { prone } \\
\text { areas }\end{array}$ \\
\hline National Road & 2.1 & 9.7 & 18.2 \\
\hline Provincial Road & 17 & 56.1 & 53 \\
\hline $\begin{array}{l}\text { Tertiary (City or Municipal or } \\
\text { Barangay or FMR or PR) }\end{array}$ & 102.3 & 22.8 & 10.5 \\
\hline Hauling Road or Pathway & 36.3 & & \\
\hline
\end{tabular}

Raw and input data source:

(1) Geohazard Maps of MGB-DENR R5

(C) LC Maps for Mt. Mayon of DENR R5

(-) OpenStreetMap contributors

() Reference from research data: Abante (2021a,b,c, 2019, 2018); Abante \& Abante (2018); Abante \& Balilo (2018)

Table 2. Road connectivity (serviceability) attribution

The road serviceability attributions in the study area as shown in Table 2 are like the road exposure stances as shown in Table 4 resulting from overlaying them with risk reality bins.

\subsubsection{OSM building footprints near protection and danger zones}

The OSM building footprints nearness (stance measurement) information when overlaid with danger zones layers, lava and/or lahar susceptibility, rain-induced or landslide prone areas provide the operational definition for exposure-stance levels. The study disclosed that there are areas that are already proclaimed as protection zones but allows production activities and road infrastructure developments. Construction of road infrastructure such as farm-to-market or hauling roads open access to bring the agricultural products to the market or to haul the gravel and sand resources needed for urban growth and economic development. However, when uncontrolled construction of buildings near or within the danger zones or lahar/lava susceptible areas along the road or pathways for dwelling purposes arise it brings in or yields exposure stances.

\subsubsection{OSM building footprints near the protection and danger} zone

Figure 10 presents the OSM building footprints and access roads that encroach the proclaimed protected area and danger zones.

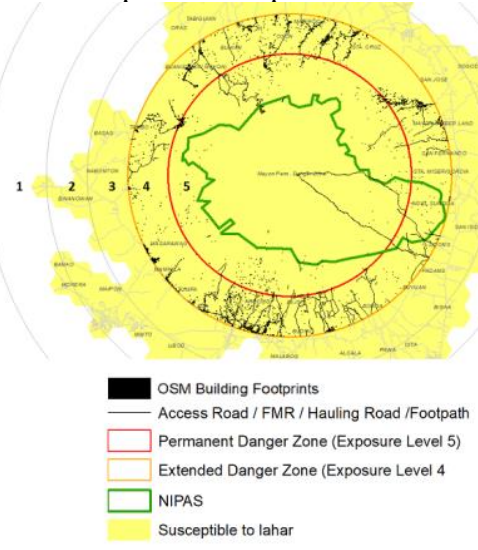

(C) Geohazard Maps of MGB-DENR R5

() OpenStreetMap contributors

() Reference from research data: Abante (2021a,b,c, 2019, 2018), Abante \& Abante (2018), Abante \& Balilo (2018)

Figure 10. OSM road and building footprints exposure levels
Combining some knowledge created by roads and building constructed within the lava flow, lahar and risk prone areas as shown in Fig.7, Figure 10 and Table 3 presents some knowledge on the OSM building counts within the moderate to extreme susceptibility to lahar (deposits) prone areas, rain-induced landslide, lava flow prone areas within the permanent and extended danger zones of Mayon Volcano as well as the encroachments happening within the proclaimed protected areas or NIPAS covered area.

\begin{tabular}{|c|c|c|c|c|}
\hline \multirow{2}{*}{\multicolumn{2}{|c|}{$\begin{array}{c}\text { Danger zones \& } \\
\text { Protection zone encroachment }\end{array}$}} & \multicolumn{3}{|c|}{ Building Count \& Exposure weight } \\
\hline & & \multirow{2}{*}{$\begin{array}{c}\text { Weight } \\
5\end{array}$} & \multirow{2}{*}{$\begin{array}{l}\text { Protection } \\
\text { zone }\end{array}$} & \multirow{2}{*}{$\begin{array}{c}\begin{array}{c}\text { Danger/ } \\
\text { Hazard } \\
\text { Zones }\end{array} \\
1,201\end{array}$} \\
\hline 1 & $6 \mathrm{Km}$ permanent danger zone & & & \\
\hline 2 & $\begin{array}{l}6 \text { to } 8 \mathrm{Km} \text { extended danger } \\
\text { zone }\end{array}$ & 4 & & 6,396 \\
\hline 3 & Extremely susceptible to lahar & 5 & & 23,993 \\
\hline 4 & Highly susceptible to lahar & 4 & & 16,468 \\
\hline 5 & $\begin{array}{l}\text { Moderately susceptible to } \\
\text { lahar }\end{array}$ & 3 & & 36,648 \\
\hline 6 & $\begin{array}{l}\text { Extremely susceptible to lava } \\
\text { flow }\end{array}$ & 5 & & 3,304 \\
\hline 7 & $\begin{array}{l}\text { Extremely susceptible to rain- } \\
\text { induced landslide }\end{array}$ & 5 & & 11,783 \\
\hline 8 & $\begin{array}{l}\text { Highly susceptible to rain- } \\
\text { induced landslide }\end{array}$ & 4 & & 586 \\
\hline 9 & $\begin{array}{l}\text { Moderately susceptible to } \\
\text { rain-induced landslide }\end{array}$ & 3 & & 6,439 \\
\hline 10 & NIPAS encroachment & & 174 & \\
\hline $\begin{array}{l}\text { Rawa } \\
\text { Geo } \\
\text { LC } \\
\text { O Ope }\end{array}$ & $\begin{array}{l}\text { input data source: } \\
\text { ard Maps of MGB-DENR R5 } \\
\text { s for Mt. Mayon of DENR R5 } \\
\text { reetMap contributors } \\
\text { ce from research data: Abante } \\
\text { Balilo (2018) }\end{array}$ & & & \\
\hline
\end{tabular}

Table 3. OSM building occurrences

\subsubsection{Risk reality vs $\operatorname{Road} \&$ building features}

The risk reality phenomenon (Abante, 2021c) was quantified using the six elements of risk. She assigned the one unit to label the near zero exposure and five units to label the exposure frequency symbolized by OSM building footprints. In this research, the risk reality phenomenon (Phi) $\mathrm{Z}$ scores and p-values measure only the statistical significance but do not reflect any kind of corrections. This study suggests additional parameters to address corrections to tweak risk reality phenomenon (Abante, 2021c).
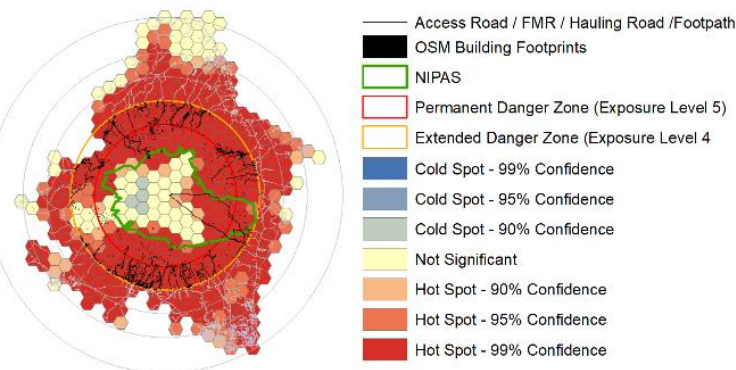

(ㄱ) Risk reality. DOI: 10.1007/s42452-021-04442-6; @ LC Maps for Mt. Mayon of DENR R5 (c) OpenStreetMap Foundation

Figure 11. Risk reality vs Road and Building Features

The risk reality bins in Figure 11 shows the bins not intersecting the road or building features are spots of insignificant risk or coldspots within or outside the network of integrated protected areas or permanent and extended danger zones. In contrast, the hexagonal bins with access roads, farm-to-market or hauling roads including footpath or pathways leading for agricultural land, quarry sites are likely located within risk hotspot patterns 
(with high numerical values are clustering) areas with $90 \%$ to 95\% level of confidence (Abante, 2021a,b,c).

Figure 11 disclose the exposure variations within cells or hexagonal bins where risk was calculated insignificant even if OSM building occurs within the extended danger zone or some part of the NIPAS covered area remain at risk with $99 \%$ risk hotspot level of confidence. The Figure also shows the hexagonal bins with $99 \%$ risk hotspot level of confidence where the OSM roads and buildings are dense.

\subsubsection{Exposure-stance context model}

The extent of roads and rising count of buildings constructed within or near the danger or hazard zones reveal changes in risk reality measurements that are dependent on exposure spatial pattern or measurement (Abante, 2021a,b,c; Abante, 2019). Such change can be visualized in terms of clustering of high numerical values brought by road extents and rising count of building footprints within the danger and hazard zones. Ending road constructions and rejecting building constructions within the permanent and extended danger zones can diffuse or disperse exposure. Dispersed exposure (perpetual relocating of exposed residents) can lower the numerical value of exposure which can reasonably reduce disaster risk. The exposure-stance contextualization highlights the paired research variables: (i) accessibility and connectivity (nearness to danger zones or uncontrolled activities within NIPAS covered area, and (ii) proximity of OSM building footprints within the danger and hazard zones.

\begin{tabular}{|c|c|c|c|c|c|c|}
\hline \multicolumn{2}{|c|}{$\begin{array}{l}\text { Exposure-stance } \\
\text { contextualization } \\
\text { parameters }\end{array}$} & \multicolumn{5}{|c|}{$\begin{array}{l}\text { Accessibility (serviceability) and } \\
\text { connectivity in Kilometer (road stances and } \\
\text { connectivity to danger zones) }\end{array}$} \\
\hline & & Level 5 & Level 4 & Level 3 & Level 2 & Level 1 \\
\hline \multirow{5}{*}{ 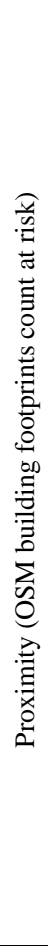 } & $\begin{array}{c}\text { OSM } \\
\text { building } \\
\text { footprints } \\
\text { within the } \\
\text { random to } \\
99 \% \text { risk } \\
\text { hotspot area }\end{array}$ & $\begin{array}{l}\text { B } 1127 \\
\text { (N 104) }\end{array}$ & $\begin{array}{l}\text { B } 1,201 \\
\text { (N 4) }\end{array}$ & $\begin{array}{l}\text { B 7 } \\
\text { (N0) }\end{array}$ & $\begin{array}{l}\text { B 48 } \\
\text { (N 14) }\end{array}$ & $\begin{array}{l}\text { B } 0 \\
\text { (N 0) }\end{array}$ \\
\hline & $\begin{array}{c}\text { concurring } \\
\text { the lava and } \\
\text { lahar prone } \\
\text { areas within } \\
\text { the } \\
\text { permanent } \\
\text { danger zone }\end{array}$ & $\begin{array}{l}\mathrm{R} 31.4 \\
\mathrm{~km} \\
(\mathrm{Nm} 8.6 \\
\mathrm{km})\end{array}$ & $\begin{array}{c}\mathrm{R} 1.4 \\
\mathrm{Km} \\
(\mathbb{N} 1.5 \\
\mathrm{km})\end{array}$ & $\begin{array}{l}\mathrm{R} 2.4 \\
\mathrm{~km} \\
\mathrm{(N2} 2.5 \\
\mathrm{~km})\end{array}$ & $\begin{array}{l}\mathrm{R} 2.5 \\
\mathrm{~km} \\
\mathrm{Nm} 2.5 \\
\mathrm{~km})\end{array}$ & \\
\hline & $\begin{array}{c}\text { OSM } \\
\text { building } \\
\text { footprints } \\
\text { within the } \\
\text { random to } \\
95 \% \text { risk } \\
\text { hotspot area } \\
\text { concurring }\end{array}$ & $\begin{array}{l}\text { B 5,578 } \\
\text { (N 43) }\end{array}$ & $\begin{array}{l}\text { B 340 } \\
\text { (N 6) }\end{array}$ & B 10 & B 72 & \\
\hline & $\begin{array}{l}\text { the lava or } \\
\text { lahar prone } \\
\text { areas or } \\
\text { agricultural } \\
\text { areas } \\
\text { classified as } \\
\text { A\&D within } \\
\text { the extended } \\
\text { danger zone }\end{array}$ & $\begin{array}{l}\mathrm{R} 112.8 \\
\mathrm{~km} \\
(\mathrm{~N} 4.3 \\
\mathrm{km})\end{array}$ & R $4.5 \mathrm{~km}$ & & $\begin{array}{l}\mathrm{R} 0.7 \\
\mathrm{~km}\end{array}$ & \\
\hline & $\begin{array}{c}\text { OSM } \\
\text { building } \\
\text { footprints } \\
\text { within the } \\
\text { random to } \\
95 \% \text { risk } \\
\text { hotspot area }\end{array}$ & В 22,025 & В 2,079 & & & \\
\hline
\end{tabular}

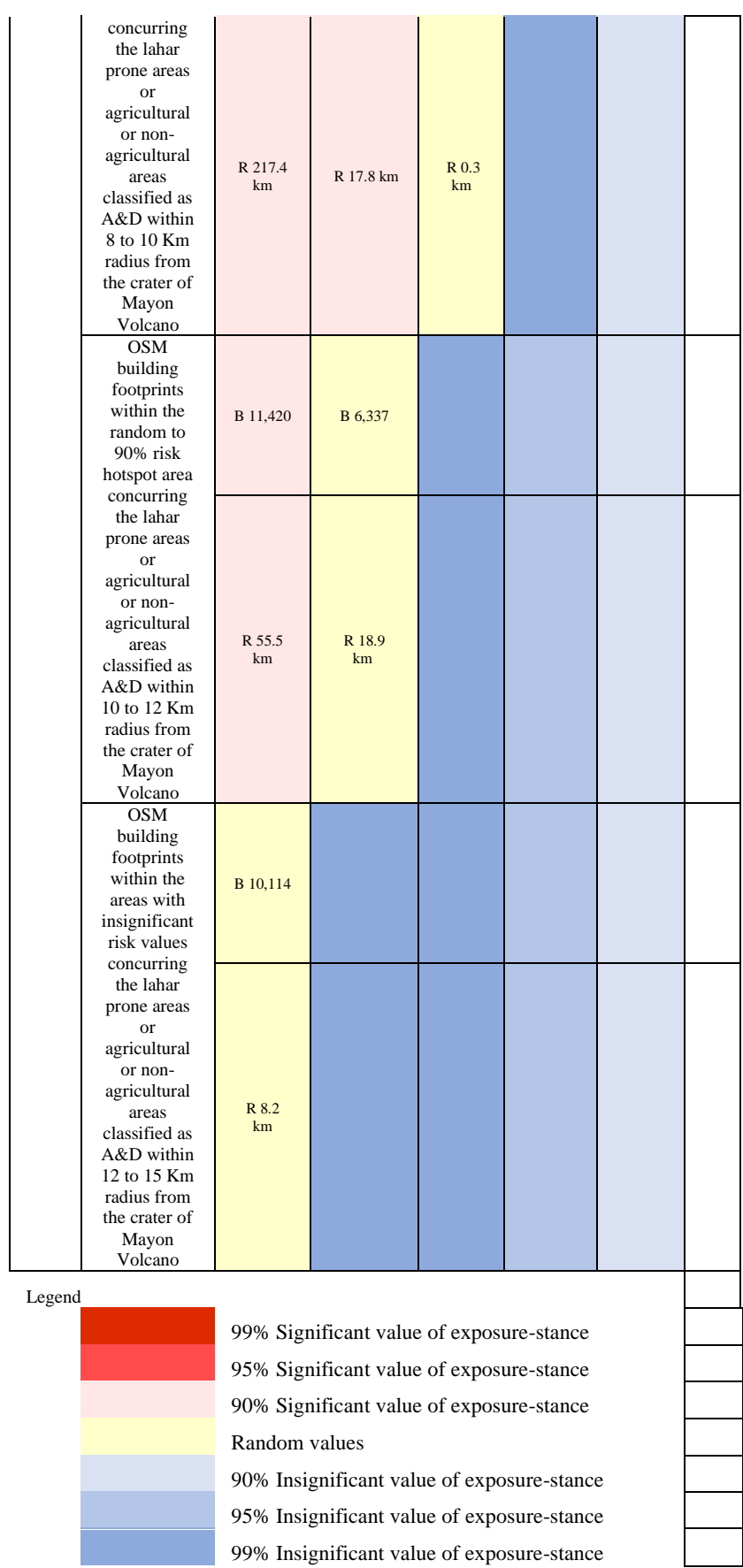

(c) Reference from research data: Abante (2021a)

Note: $B \rightarrow$ Building; $N \rightarrow$ Building within NIPAS covered area; $R \rightarrow$ road network or farm-tomarket or hauling pathways or access to forest, agricultural, quarry sites and dwelling sites.

Table 4. Exposure-stance contextualization matrix

Table 4 disclosed exposure-stances based on the five pairs of exposure-stances contexts that creates knowledge prompted by spatial information (nearness measurements) on accessibility, connectivity, proximity, risk reality, danger and hazards zones, and OSM roads and building footprints variables and features. It presents new knowledge based on the analytical data derived from overlaying spatial and non-spatial information about protection and production areas, benefits and threats of providing access. It creates some knowledge on exposure that depends on the rising of building counts and extent of road networks encroaching the danger, hazard and protection zones within the study area. This can help readers to see the significance of the resulting statistics based on the research variables on examining impacts of road and building 
construction relative to the extraneous error in risk computing and land use planning.

The accessibility (road stance serviceability) and connectivity (nearness to danger zones or uncontrolled activities within NIPAS covered area are categorized into the following: (i) Level 1 conveys the road stances and connectivity within the 12 to 15 $\mathrm{Km}$ proximity reckoned from the center on the crater of the volcano; (ii) Level 2 conveys the road stances and connectivity within the 10 to $12 \mathrm{Km}$ proximity reckoned from the center on the crater of the volcano; (iii) Level 3 conveys the road stances and connectivity within the 8 to $10 \mathrm{Km}$ proximity reckoned from the center on the crater of the volcano; (iv) Level 4 conveys the road stances and connectivity within the 6 to $8 \mathrm{Km}$ proximity reckoned from the center on the crater of the volcano or the extended danger zone; and (v) Level 5 conveys the road stances and connectivity within the $6 \mathrm{Km}$ Mayon permanent danger zone.

The proximity in this study is regarded as OSM building footprints existences within the danger zones and NIPAS covered area are categorized into the following: (i) OSM building footprints within the 90 to $99 \%$ risk hotspot area concurring the lava and lahar prone areas within the permanent danger zone; (ii) OSM building footprints within the 90 to $99 \%$ risk hotspot area concurring the lava or lahar prone areas or agricultural areas classified as A\&D within the extended danger zone; (iii) OSM building footprints within the 90 to $99 \%$ risk hotspot area concurring the lahar prone areas or agricultural or non-agricultural areas classified as A\&D within 8 to $10 \mathrm{Km}$ radius from the crater of Mayon Volcano; (iv) OSM building footprints within the 90 to $99 \%$ risk hotspot area concurring the lahar prone areas or agricultural or non-agricultural areas classified as A\&D within 10 to $12 \mathrm{Km}$ radius from the crater of Mayon Volcano; and (v) OSM building footprints within the 90 to $99 \%$ risk hotspot area concurring the lahar prone areas or agricultural or non-agricultural areas classified as A\&D within 12 to $15 \mathrm{Km}$ radius from the crater of Mayon Volcano.

The exposure-stance contextualization offers visualization of how people living at the foot slopes of Mayon volcano or their goods and agricultural products or gravel and sand hauling are transported from place to place near the protection and danger zones. The connectivity information deals with the geographical locations to be reached from or to be reached by to transport people and goods or resources within or beyond the extended danger zone. The exposure-stance contextualization matrix as shown in Table 4 plainly provides a new way to characterize the road network development and increasing encroachments within the protected and dangerous areas in the upper environ of the volcano.

\section{CONCLUSIONS}

The accessibility, road network connectivity and proximity to danger, hazard and protection zones parameters traversing the vulnerable host environment susceptible to physical changes mimics the implications of utilizing the protection/production zones to harvest or extract resources. The exposure-stance substantiates either risk reduction or increase the risk quantity built by constructing more roads and buildings in the host environment. Nulling exposure variable if not dispersing exposure stances within the protected areas, development constraint areas, and permanent and extended danger zones of Mayon Volcano has a practical implication to stabilize and sustain developments.
The study concluded that rejecting (through geospatial information modeling by deleting line and polygon features mimics the perpetual relocation of exposed residents) road and building constructions within the danger and hazard zones really reduce disaster risks. Also, closing the NIPAS covered area to any activities will likely nil exposure, thus lowering risk hotspot level of significance when this protected area is fully reverted as forest zone. Hence, nullifying exposure if not dispersing exposure stances within the protected areas, development constraint areas, and permanent and extended danger zones of Mayon Volcano has a practical implication to stabilize and sustain developments at the foot slopes of the volcano.

\section{REFERENCES}

Abante, A. M. R., 2021a. Manuscript on Exposure-Stance GIS Model. Bicol University.

Abante, A. M. R., 2021b. Manuscript on GIS Model to Contextualize the Advanced Preparedness and Adaptive Capacity for DRRM. Bicol University.

Abante, A. M. R., 2021c. Geophilosophical realness of risk: a case study in national housing authority resettlement sites in Albay, Philippines. SN Applied Sciences, 3(4), 1-22.

Abante, A. M. R., 2019. The Exposure-Happenstance Concept Model: A Case Study Within the Foot Slopes of Mayon Volcano, Albay, Philippines. In Euro-Mediterranean Conference for Environmental Integration (pp. 2031-2037). Springer, Cham.

Abante, A. M. R., \& Abante, C. G. R., 2019. TOPOPHILIAEXPOSURE CENTRAL SPACE CONCEPT MODEL. International Archives of the Photogrammetry, Remote Sensing \& Spatial Information Sciences.

Abante, A. M. R., \& Abante, C. G. R., 2018. Sensitive Land Use Planning, Malinao, Albay, Philippines. In IOP Conference Series: Earth and Environmental Science (Vol. 123, No. 1, p. 012001). IOP Publishing.

Abante, A. M. R., \& Balilo Jr, B. B., 2018. Resource LocationIntelligence Model Conceptualized for Mayon Volcano Danger Zones in Albay, Philippines. International Journal of Computing Sciences Research, 2(2), 55-67.

Abante, A. M. R., 2018. Understanding preparedness insufficiency in the context of DRRM: a case study in Malinao, Albay, Philippines. In Conference of the Arabian Journal of Geosciences (pp. 497-501). Springer, Cham.

Ariel, M., 2001. Accessibility theory: An overview. Text representation: Linguistic and psycholinguistic aspects, 8(8).

Bankoff, Greg, Chris Newhall, and Alicia Schrikker. "The Charmed Circle: Mobility, Identity and Memory around Mount Mayon (Philippines) and Gunung Awu (Indonesia) Volcanoes." Human Ecology 49, no. 2 (2021): 147-158.

Feldmeyer, Daniel, Claude Meisch, Holger Sauter, and Joern Birkmann. "Using OpenStreetMap data and machine learning to generate socio-economic indicators." ISPRS International Journal of Geo-Information 9, no. 9 (2020): 498.

Hansen, W. G., 1959. How accessibility shapes land use. Journal of the American Institute of planners, 25(2), 73-76. 
Higgins, E. T., Rholes, W. S., \& Jones, C. R., 1977. Category accessibility and impression formation. Journal of experimental social psychology, 13(2), 141-154.

Lee, T. A., \& Pickard, A. S., 2013. Exposure definition and measurement. In Developing a Protocol for Observational Comparative Effectiveness Research: A User's Guide. Agency for Healthcare Research and Quality (US).

Levinson, D., \& Huang, A., 2012. A positive theory of network connectivity. Environment and planning B: Planning and design, 39(2), 308-325.

Milla, K., Thomas, M., \& Ansine, W., 2005. Evaluating the effect of proximity to hog farms on residential property values: A GISbased hedonic price model approach. URISA Journal, 17(1).

Corcoran, P., Mooney, P., \& Winstanley, A. C., 2010. Topological consistent generalization of OpenStreetMap.

Olsson, J., 2009. Improved road accessibility and indirect development effects: evidence from rural Philippines. Journal of Transport Geography, 17(6), 476-483.

Ramm, F., Names, I., Files, S. S., Catalogue, F., Features, P., Features, N., \& Cars, C., 2014. OpenStreetMap data in layered GIS format. Version 0.6, 7 .

Shaohua, W. A. N. G., Ershun, Z. H. O. N. G., Huajun, L. I. A. O., Yao, Z. U. O., Wenwen, C. A. I., \& Liang, L. O. N. G., 2017. Research on Road Network Characteristics Based on Proximity Graph. Bulletin of Surveying and Mapping, (8), 80.

Thépaut, Jean-Noël, Dick Dee, Richard Engelen, and Bernard Pinty. "The Copernicus programme and its climate change service." In IGARSS 2018-2018 IEEE International Geoscience and Remote Sensing Symposium, pp. 1591-1593. IEEE, 2018.

Wei, Y., Wang, H., Tsang, K. F., Liu, Y., Wu, C. K., Zhu, H., ... \& Hung, F. H., 2019. Proximity environmental feature-based tree health assessment scheme using Internet of Things and Machine Learning algorithm. Sensors, 19(14), 3115. 